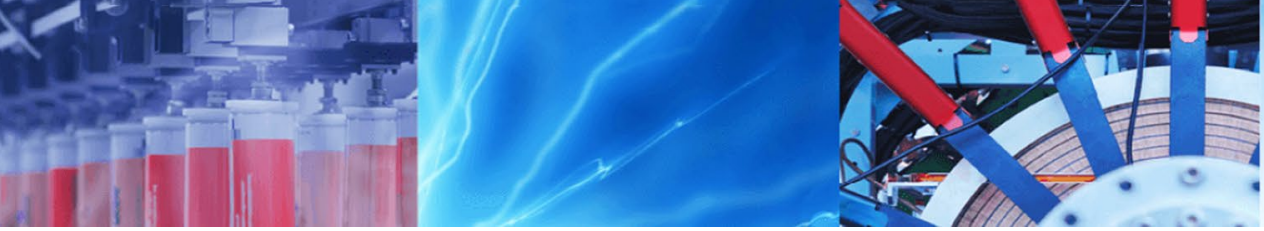

Case Study

\title{
Comparative numerical study for polymer alternating gas (PAG) flooding in high permeability condition
}

\author{
Azza Hashim Abbas ${ }^{1,2}$. Dhiya Shabana Abdullah ${ }^{1} \cdot$ Mohd Zaidi Jaafar $^{1} \cdot$ Wan Rosli Wan Sulaiman ${ }^{1} \cdot$ Augustine Agi $^{1}$
}

Received: 2 October 2019 / Accepted: 2 April 2020 / Published online: 20 April 2020

(c) Springer Nature Switzerland AG 2020

\begin{abstract}
Polymers have been used in water alternative gas, to viscosify the water and improve the overall sweep efficiency. The use of polymer alternative gas was successful in increasing the oil production in high permeability zones. However, few practical factors affecting the field applicability have been overlooked. Therefore, this study is aimed at bridging the gap between the possibility of using several EOR such as water flooding, $\mathrm{CO}_{2}$ flooding, water alternative gas, polymer flooding and polymer alternative gas. The research based on progressive comparison considering constant constraint. The numerical simulation STARS-CMG was used to predict the characteristics and behaviour of the fluid in the reservoir. The designed flooding pattern chosen was a single producer-single injection (P-I) scheme in homogeneous high permeable reservoir. The results of oil incremental recovery showed the following order compared to Water flooding $<(3 \%) \mathrm{CO}_{2}$ flooding $<(6.8 \%)<$ Water alternative gas $(11.6 \%)$ Polymer flooding $<(15 \%)$ Polymer alternative gas. The impact of polymer on enhancing the water alternative gas was mostly noticeable in the reduction of water cut $\%(83 \%)$. The controlled conformance by polymer aided in improving the sweep efficiency as indicated by the uninform U-shape. Moreover, the delayed gas breakthrough was significant and resulted in the lowest gas oil ratio of $5.17 \mathrm{E}+04 \mathrm{ft} 3 / \mathrm{bbl}$. The low gas oil ratio observation is indication of potential capturing of $\mathrm{CO}_{2}$ in the reservoir and thus, good evidence to further implementation of $\mathrm{CO}_{2}$ as green utilization.
\end{abstract}

Keywords Polymer water alternative gas flooding $\cdot$ Line drive pattern · Gas oil ratio $\cdot$ Incremental recovery $\cdot$ Sweep efficiency

\section{Introduction}

Enhanced oil recovery (EOR) methods are employed to increase the production of hydrocarbon from the reservoirs after primary and secondary recovery. One of the techniques that was employed successfully is gas flooding. Gas flooding projects are part of EOR since 1960s and considered profitable in both conventional and unconventional reservoirs [1]. However, the type of gases used may hinder the technical feasibility if it is not compatible with the application conditions. Ideally, $\mathrm{CO}_{2}$ releases oil by aiding several mechanisms such as; improving the microscopic efficiency, lowering the interfacial tension (IFT) at the miscible condition and reduce the oil density [2]. At present, $\mathrm{CO}_{2}$ flooding has been designated as a beneficial method to decrease the global warming and reducing the greenhouse gas emissions [3]. However, several problem remained unsolved such as; gas fingering, operating parameters and the pressure depletion rates [4]

As part of utilizing $\mathrm{CO}_{2}$ flooding, a new flooding strategy that includes the presence of water flooding, was proposed by Parrish (1966). It has the potential to attain

\footnotetext{
$\triangle$ Mohd Zaidi Jaafar, mzaidi@utm.my | ${ }^{1}$ Department of Petroleum Engineering, School of Chemical and Energy Engineering, Faculty of Engineering, Universiti Teknologi Malaysia, 81310 Johor Bahru, Malaysia. ${ }^{2}$ School of Computing, Engineering.and Technology, Asia Pacific University of Technology \& Innovation (APU), 57000 Kuala Lumpur, Malaysia.
} 
higher mobility control and enhance volumetric sweep efficiency over solo $\mathrm{CO}_{2}$ injection [5]. This technique known as water alternating gas (WAG), which includes injecting water and gas alternately or simultaneously and each duration is referred to as cycle. Despite the success of $\mathrm{CO}_{2}$-WAG, the challenge is achieving the field incremental recovery, which is between 5 and 10\% OOIP [6]. This low production is due to gravity segregation effect, water blocking phenomena and WAG mobility control [7]. Also, the method faced significant challenge in improving sweep efficiency in high permeable zones. The gravity segregation effect arises during the injected fluid movement towards the production wells and resulted in water blocking the residual oil from contacting $\mathrm{CO}_{2}$ [8]. The mobility control of WAG is not feasible especially in high or medium viscosity oil. In high viscous oil reservoirs, the oil and water mobilities are low therefore, the mobility ratio will be high. If mobility ratio $(M)>1$, it will not be a favourable condition as it promotes viscous fingering occurrence [9].

For all the previous -mentioned reasons, $\mathrm{CO}_{2}$-WAG approach was subjected to enhancement by chemicals such as; surfactants, polymers, nanoparticles [10, 11]. Polymer was proposed to overcome the problems of gas breakthroughs and gravity segregation by using polymers. Polymer alternating gas (PAG), combines the elements of $\mathrm{CO}_{2}$ flooding with polymer flooding to enhance the sweep efficiency especially in high permeable zones [12-14]

Polymer gas alternating water (PGAW) has been experimented on Canadian heavy crude oil and the results were promising [15]. The study compared, four techniques of flooding, $\mathrm{CO}_{2}$ immiscible flooding, WAG, polymer and PAG. The results showed that low concentration of polymer (0.2 wt\%) used in PAG injection recovered more oil than the polymer flood with double concentration. Another observation was that the $\mathrm{CO}_{2}$ in PAG used only $30 \%$ to recover the same oil recovered by the continuous $\mathrm{CO}_{2}$ flooding. The combination of polymer with $\mathrm{CO}_{2}$ is beneficial in improving the recovery more than single component techniques [15]. Despite the difficulty in optimizing the injection of polymer and $\mathrm{CO}_{2}$ in core scale, it was more successful on simulation and numerical level. Accordingly, a sophisticated model was built to compare different injection strategies in controllable injection rate of $3000 \mathrm{bbl} /$ day. However, the combination of $\mathrm{CO}_{2}$ and polymer was assisted by surfactant and alkali, which makes the increase in the recovery not directly related to the polymer [16]. Li and schechter in 2014, performed a detailed numerical study on PAG for North Burbank Unit in Oklahoma, USA. The targeted reservoir categorized as highly heterogeneous with high permeability at the top layers and decreasing downward. In the first phase of the study they compared homogeneous and heterogeneous synthetic reservoir model, to optimize the polymer concentration. They used three different polymer concentration of $0.1 \mathrm{lb} / \mathrm{STB}, 0.2 \mathrm{lb} / \mathrm{STB}$ and $0.3 \mathrm{lb} / \mathrm{STB}$. The highest oil recovery factor (RF) for PAG was about $19.7 \%$, the recovery improved up to $12 \%$ compared to WAG, however this result was obtained at polymer concentration of $0.2 \mathrm{lb} / \mathrm{STB}$ [12]. In the second case study, they compared the effect of several flooding scenarios including $\mathrm{CO}_{2}$ injection, WAG, polymer flooding and PAG. Although, the polymer concentration was reduced, additional oil RF of $12 \%$ was obtained [11]. However, the study was limited in demonstrating the influence of each scenario on gas production, water production and residual oil saturation. Another simulation study done by Jeong et al. (2014) in heterogeneous model considered four scenario, water flooding, $\mathrm{CO}_{2}$ flooding, WAG and PAG. The results showed good mobility ratio and the PAG process represented the highest oil recovery factor of $37 \%$. However, the result showed high improvement compare to the previous work in North Burbank Unit, which might be due to the porosity and permeability characteristic of the synthetic model [17].

Another simulation study for Cranfield reservoir in Mississippi, considered as a pilot test to understand the role of oil phase behaviour on different flooding scenarios. The study confirmed that PAG is had the highest recovery with $74 \%$ oil RF [18]. However, the study used multiple injectors, which made the effect of injection rate dominant in the scheme of the work. An optimization study for PAG process selected polymer concentration as dominant factor to improve the PAG efficiency [19]. However, the study suggested that the challenges of using PAG is not limited to concentration but it gas injected volume, injection rate and injection wells allocation may alter the operation recovery and the overall recovery obtained. A heterogeneous numerical model for PAG was investigated using a geological model of Liaohe Oilfield in China. The result showed that the effect of PAG is not satisfactory in high viscous heterogeneous reservoirs, however it has a major effect on water cut reduction [20].

Previous studies focused on the use of $\mathrm{CO}_{2}$ flooding in moderate to high permeable reservoirs. However, there is controversy surrounding the synergy between $\mathrm{CO}_{2}$ and chemicals in the field application. Therefore, this systematic study aimed to compare the oil recovery factor between PAG flooding, polymer flooding, WAG flooding, gas flooding and water flooding. Secondly, to evaluate the impact of each process on other important factors such as; mobility, GOR, water cut and saturation distribution. Also, the comparison meant to give an insight on the potential use of PAG in improving the oil production and the flow behaviour. 


\section{Methodology}

\subsection{Modelling scheme and selection prospective}

To perform numerical modelling, the CMG-STARS software was used to study the water flood, $\mathrm{CO}_{2}$ flood, WAG flood, polymer flood and PAG flood in this study. STARS is known to be a powerful tool for three-phase and multi-component additives. The numerical equation was solved as fully implicit or adaptive implicit formulation to assure fast running time and flexibility for users. Moreover, STARS have numerous features which makes the study visible for all the chosen variables. Moreover, the CMG suits provide a 3D RESULT display option, which ease the comparison of chemical dispersion for multiple models at the same time.

The study working scheme was designed including several stages: modelling the area, defining the flooding scheme and analysing the outputs. The study development stages are schematically illustrated Fig. 1

Fig. 1 Simulation workflow

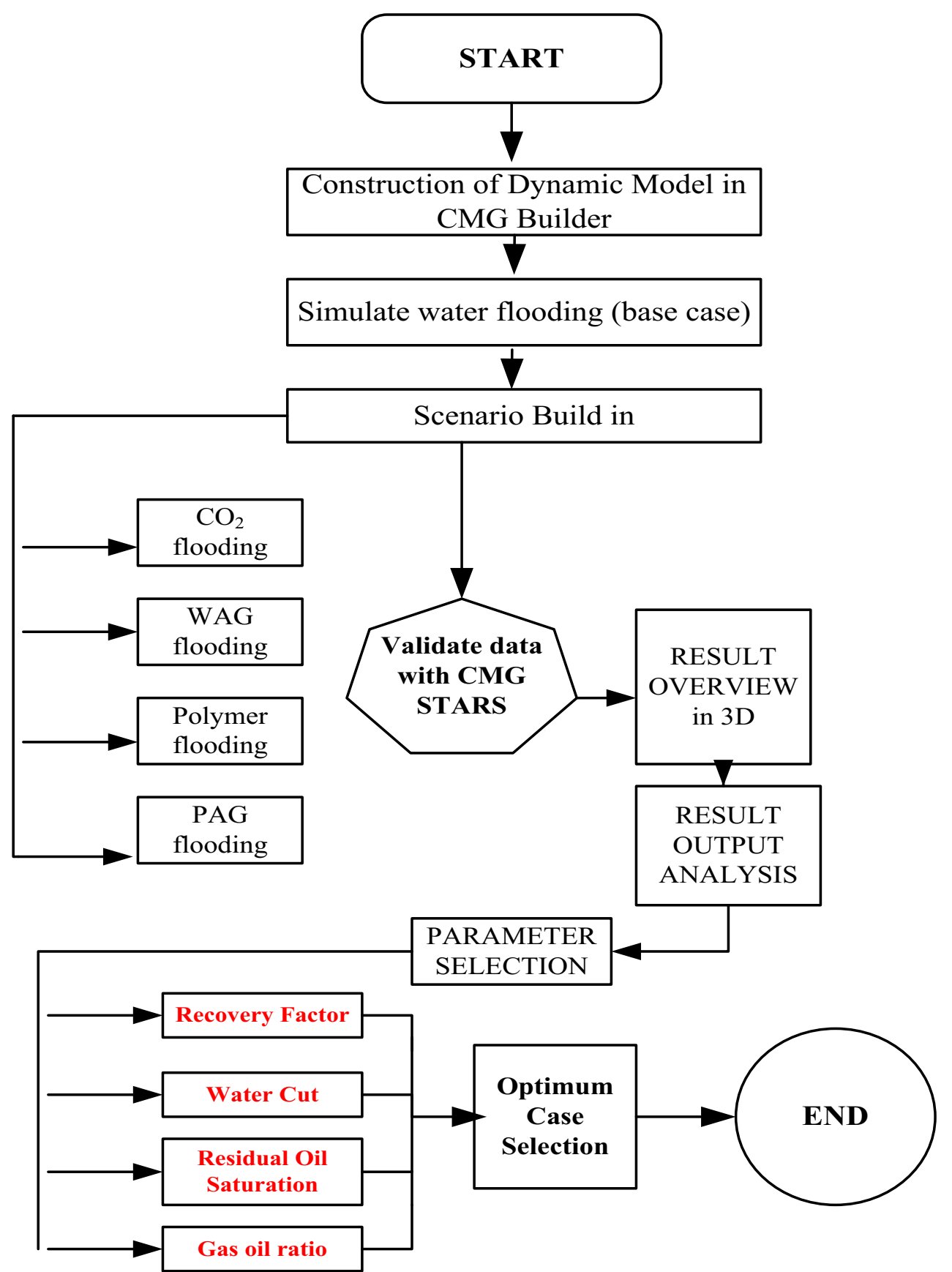


The work development as shown in Fig. 1 represents numerical study that compares several processes. The numerical analysis was built to evaluate each of the processes without changing any flow constrain. Moreover, the evaluation was based on four selected output parameters.

The numerical model was created for sandstone reservoir and represented by cartesian grids. The hypothetical reservoir assumption was homogeneous in nature; thus, the grids were represented by uniformed thickness. The grid design was adequate for the desired numerical accuracy and demonstration of fluid displacement process. The base input parameters for reservoir grid are presented in Table 1.

\subsection{Reservoir rock and fluid properties}

In order to give the best realistic fluid behaviour, the reservoir rock and fluid properties were to some extend based on previous study in North East Africa [10]. Few assumptions were made prior to numerical implementation such as; gravity and capillary pressure were neglected; rock and fluid were assumed incompressible and the medium as homogeneous and isotropic (porosity and permeability are constant). The oil model used was dead oil (no dissolved gas) and light oil (10 cp).

Table 1 General properties of reservoir model

\begin{tabular}{ll}
\hline Parameter & Value \\
\hline Top reservoir depth & $7865 \mathrm{ft}$ \\
Number of grids & $10 \times 10 \times 3$ \\
Grid thickness & $10 \mathrm{ft}$ \\
Active blocks & 300 \\
\hline
\end{tabular}

Liquid phase characteristics was interpolated using Standing's correlation in builder, the main inputs are pressure and temperature (Table 2). The use of the correlation helps to speed up the software running time and consequent changes adaptation. The relative permeability curve was generated by selecting the endpoint scaling for the consolidated sandstone and input the initial saturation condition as presented in Table 2 and Fig. 2. The relative permeability curve in Fig. 2 represents a water wet reservoir, where the synthetic system is good candidate for gas and chemical tertiary recovery.

\subsection{Wells and operation constrains}

The mode of well was defined for single well producerinjector (P-I), the scheme chosen to detect preferential flow trends and to further investigate the sweep efficiencies; and the success of any flooding. The injection well and producing wells were open in the whole three layers

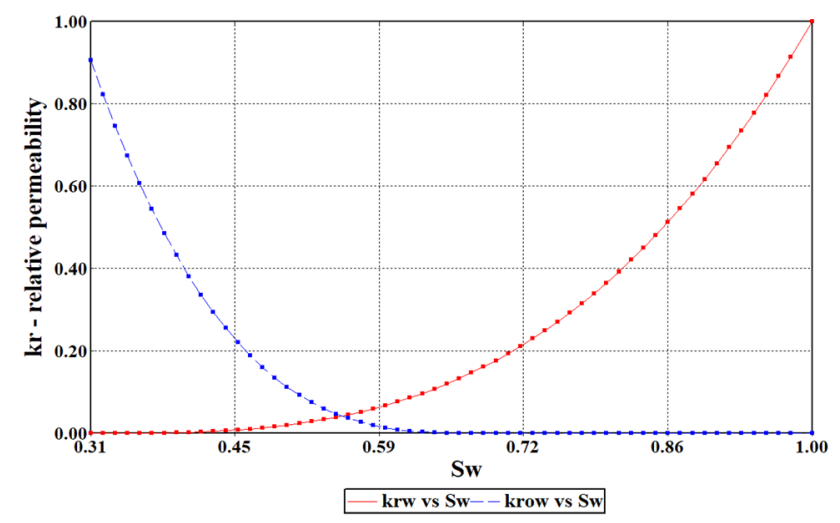

Fig. 2 Generated relative permeability curve
Table 2 Rock and fluid input data

\begin{tabular}{lll}
\hline Information & Parameter & Value \\
\hline Rock properties & Rock density & $0.1654 \mathrm{lb} / \mathrm{ft}^{3}$ \\
& Porosity (homogeneous) & $25 \%$ \\
& Permeability I direction & $800 \mathrm{mD}$ \\
& Permeability J direction & $800 \mathrm{mD}$ \\
& Permeability K direction & $260 \mathrm{mD}$ \\
Fluid properties & Oil density & $49.1 \mathrm{lb} / \mathrm{ft}^{3}$ \\
& Oil viscosity & $10 \mathrm{cp}$ \\
& Water density & $64.79 \mathrm{lb} / \mathrm{ft}^{3}$ \\
& Water viscosity & 0.89 \\
Initial reservoir conditions & CO 2 Minimum Miscibility Pressure & $2000 \mathrm{psi}$ \\
& Pressure & $3500 \mathrm{psi}$ \\
& Temperature & $100^{\circ} \mathrm{F}$ \\
& Initial oil saturation & 0.69 \\
\hline
\end{tabular}


and horizontally in line to assure the maximum degree of communication in the (P-I) system. The selected locations and completion facilitate managing any floods, particularly at these selection stages. Wells location are shown in Fig. 3. The constrain assumption was controlled by the minimum bottom hole pressure for producer and by maximum allowable head pressure for the injector. Injector was controlled by a certain fluid constrain that is specified in Table 3.

\subsection{Numerical study and cases illustration}

A total of five cases were used for this simulation work. The first scenario is a base case of continuous water injection also it worth to noted that no chemical was added at this stage. The water flooding continued as long as the oil could be produced, the practice considered under secondary recovery and a mandatory stage for economic comparison. The second scenario created is the $\mathrm{CO}_{2}$ flooding, which represent the continuous injecting of the gas. The third scenario is the WAG flooding (at ratio 1:2). With 2 months of $\mathrm{CO}_{2}$ injection, followed by 2 months of water injection. The fourth scenario is flooding using polymer, the polymer selecting criteria is illustrated in the following section. The last scenario is the PAG which was a combination of polymer and gas alternate injection. The input for numerical convergence was chosen to avoid disturbance in the overall system during the runs. The time step applied for the events in the simulation is 60 days. The simulation is run for 5 years, starting from the year 2018-2023, for a total of 1643 days.

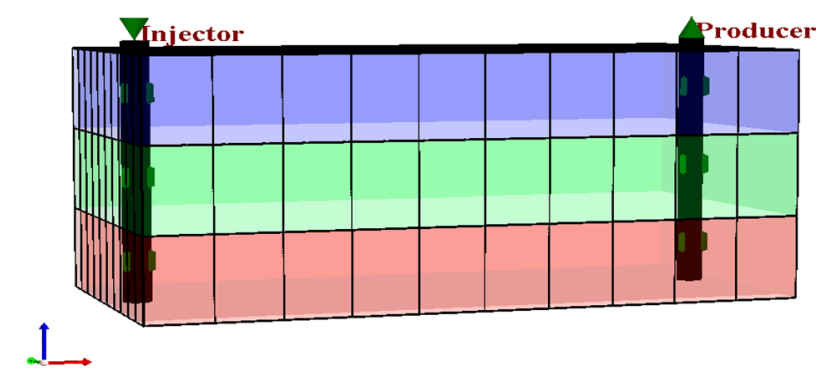

Fig. 3 Injector and producer wells location

\subsection{Polymer flooding}

All the constraints applied for the previous scenarios are kept constant for both polymer and PAG flooding. The polymer used is polyethylene glycols, PEG concentration used was 2000 ppm similar constant values were used in pilot test $[21,22]$. The selection of the polymer concentration was based on the acceptable range of polymer flood reported for similar range of porosity and permeability, which is between 500 and 3000 ppm [23]. The polymer viscosity parameter was used for both cases as shown in Table 4[24]. The polymer viscosity is also non-Newtonian and depends on the shear rate or rate of flow, exhibiting shear thinning behaviour. The simulator (CMG-STARS) is capable of modelling linear and non-linear mixing of polymer injection process, and non-Newtonian viscosity. Polymer mixing rule in CMGSTARS is as follow,

$\ln \mu=\sum_{i=s} f_{i}\left(x_{i}\right) \ln \mu_{i}+N \cdot \sum_{i \neq s} x_{i} \ln \mu_{i}$

In which $f_{s}\left(x_{s}\right)$ is the viscosity mixing function through input table for key component $s$ (polymer), $N\left[1-f_{s}\left(x_{s}\right)\right] /$ $\left(1-x_{s}\right)$. For linear mixing, $f_{s}\left(x_{s}\right)=\left(x_{s}\right), N=1$

Shear thinning rheology is applied for the polymer flood. The calculated Darcy velocity $\left(\mu_{1}\right)$ and input reference Darcy velocity are used to quantify the shear rate. Polymer adsorption is modelled based on Langmuir isotherm.

Table 4 Polymer concentration in water $\%$ and corresponding viscosity

\begin{tabular}{ll}
\hline Water + polymer viscosity $(\mathrm{cp})$ & $\begin{array}{l}\text { Polymer concen- } \\
\text { tration in water } \\
(\mathrm{wt} \%)\end{array}$ \\
\hline 0.89 & 0 \\
3.5 & 0.03 \\
5.2 & 0.05 \\
10.8 & 0.075 \\
\hline
\end{tabular}

Table 3 Well simulation constraints input

\begin{tabular}{lll}
\hline Well & Parameter & Value \\
\hline Injector well & Maximum bottom hole pressure (BHP) & 3600 psi \\
Injector well & Maximum water rate (BHW) & $1200 \mathrm{STB} /$ day \\
Injector well & Maximum gas rate (BHG) & $200 \mathrm{MMSCF} /$ day \\
Production well & Minimum bottom hole pressure (BHP) & 200 psi \\
\hline
\end{tabular}




\section{Recovery Factor Result Summary}

5 Cases

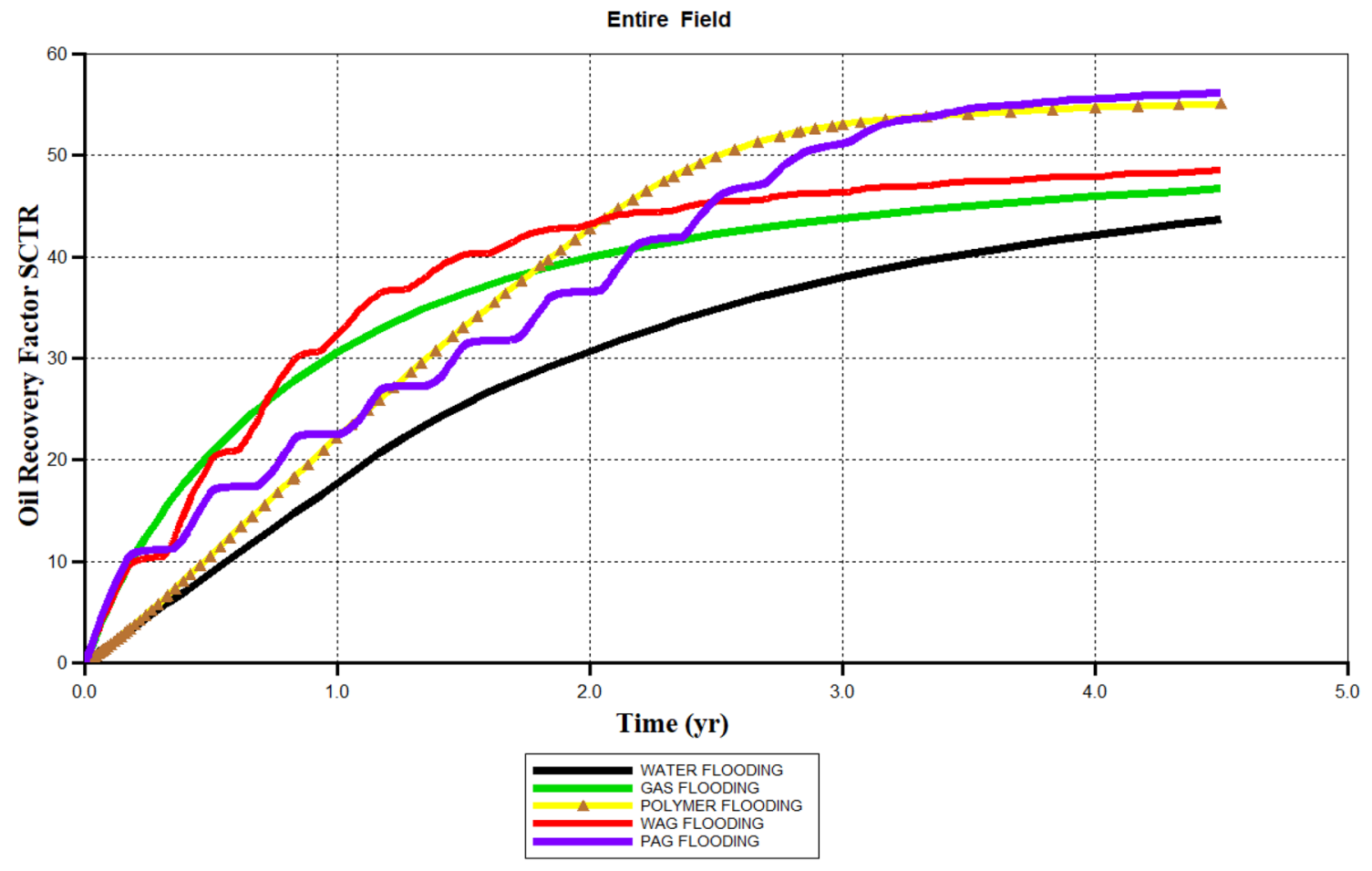

Fig. 4 Oil Recovery factor for 5 cases of flooding

\section{Results and discussion}

\subsection{Oil recovery results}

The result of oil RF for the 5 cases were compared using the CMG-graph result software as shown in Fig. 4. The oil $\mathrm{RF}$ was low for the water flooding (base case) which is about $43.7 \%$. The recovery factor obtained by gas, WAG and polymer was $(46.5 \%, 50.9 \%, 54.1 \%)$ respectively. The highest oil RF was 56\% (PAG flooding).

The oil recovery after water flooding was affected by the difficulty in exploitation of viscous oil. Similar results were observed by Gao (2011) and Bento and Moreno (2016). They reported a low oil RF due to the adverse mobility ratio and early water production, which is more intense during the high viscosity oil exploitation. $\mathrm{CO}_{2}$ flooding has an incremental oil RF of $3 \%$, the slightly increase in oil recovery can be attribute to the injection pressure and the reservoir high permeability. However, the gas flooding also contributed to the oil viscosity reduction, and thus increase in oil RF [25]. Similar results was also observed in 1986 for the case of Rangely Weber Sand Unit, the gas flooding was not sufficient to increase the oil RF due to insufficient miscibility and high reservoir permeability [26]. Moreover, the gas mobility about $46,000 \mathrm{md} / \mathrm{cp}$ for layer
1 and decreased in vertical direction up to $40,000 \mathrm{md} / \mathrm{cp}$ and $12,000 \mathrm{md} / \mathrm{cp}$ at layer 2 and 3 respectively.

For $\mathrm{CO}_{2}$-WAG flooding the incremental recovery was $6.8 \%$, which is more likely due to the sweeping efficiency enhancement and microscopic-oil displacement efficiency. Despite the limited understanding of WAG injection mechanism, the result of this study was similar to previous study for homogeneous and heterogeneous reservoir, which was between 7 and 9\% [27]. The oil recovery was attributed to the cycle process that reduced the gas mobility, the gas mobility was $11,225 \mathrm{md} / \mathrm{cp}, 547 \mathrm{md} / \mathrm{cp}$ and 0 for layer 1, 2 and 3 respectively.

The polymer flooding showed improvement in the incremental recovery up to $11.6 \%$. The concept of improving the oil production by polymer flooding has always been related to viscoelasticity of water in sweep efficiency improvement. The recovery results is consistence with the limit of injection constrain of this study and shear thickening behaviour that restrain the polymer injectivity rates $[28,29]$.

The oil recovery enhanced by PAG has additional $1.3 \%$ due to the improvement in mobility control. Similar results were observed by previous study of $\mathrm{Li}$ et al. (2014) for homogeneous models up to $500 \mathrm{mD}$ permeability. The results of this study whereby for a

\section{SN Applied Sciences}




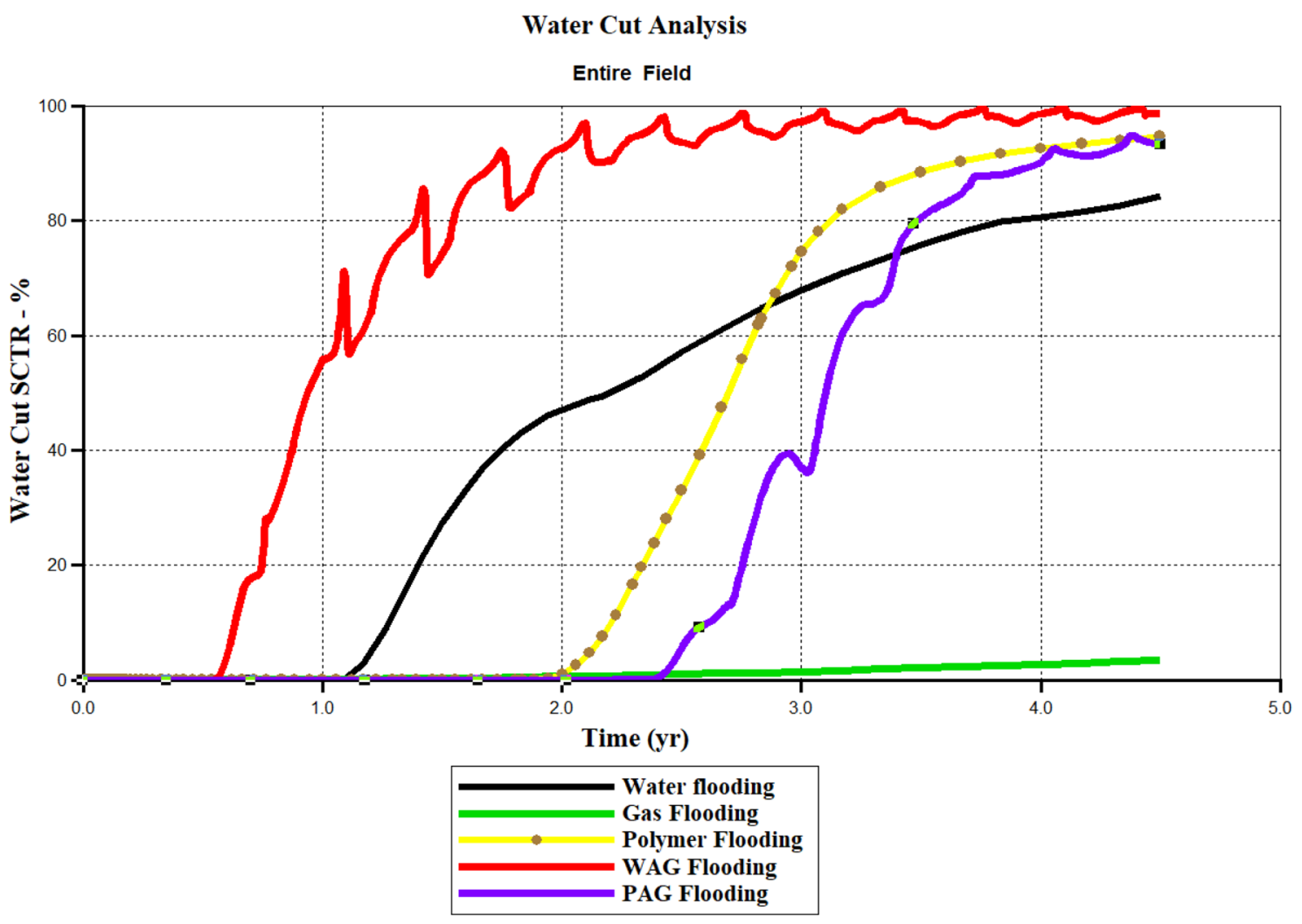

Fig. 5 Water Cut in different flooding cases

homogeneous reservoir with $800 \mathrm{mD}$, the PAG was giving additional $7.5 \%$ oil RF compared to $\mathrm{CO}_{2}$-WAG flooding of $7-15 \%$ [11].

\subsection{Water cut analysis}

Water cut is a very sensitive factor in deciding the suitability of EOR process in mature oil field. The result in Fig. 5 shows water cut of $(98.6 \%, 93.6 \%, 92 \%, 84 \%, 5 \%)$ for WAG, Polymer, PAG, Water flooding and gas respectively. The highest water cut during the WAG flooding. This is attributed to the changing of relative permeability curve in the presence of three phase flow [30].Taking into account the phase behaviour complexity and flow characteristics variation, it revealed that the behaviour of water cut was higher than expected. Similar observation was reported by [31] as the numerical software tends to enhance the relative permeabilities curves continuously, especially when all phases are mobile. The polymer flooding and PAG flooding also indicated high water cut but lower than WAG, which may be related to the water movement restriction because of viscosity improvement.

\subsection{Residual oil saturation (Sor)}

\subsubsection{Sor after water flooding}

The measurement of Sor is of paramount importance in understanding the recovery in a producing field. For the water flooding (base case), the initial oil saturation was about 0.69 and the $\mathrm{S}_{\text {or }}$ map showed a uniformity over all the grid as shown in Fig. 6a. Once the water flooding started, it pushed the oil near the injector well (in the first grid) to the producer well (in the last grid). At the end of the water flooding (the water cut was $84.2 \%$ ), the $\mathrm{S}_{\text {or }}$ map looks like Fig. $6 \mathrm{~b}$. The shape of oil mobilization in one direction and layer 1 indicate a transfer of shape between $v$ to non-uniform $U$. It demonstrates that the sweeping of oil appeared to be non-homogenous and the maximum oil swept belonged to the area near the injector well. Since, water flooding in this study occurs in a water-wet rock reservoir; higher Sor was expected. Moreover, the effective water flooding to mobilize viscous oil is hindered by the reverse mobility ratio and by capillary and wettability of the water wet system. Thus, $\mathrm{S}_{\text {or }}$ for water flooding was found to be in the range of 0.44 and huge amount of oil was still un exploited [10]. 
Flooding Scenario

Water flooding

Gas flooding

WAG flooding

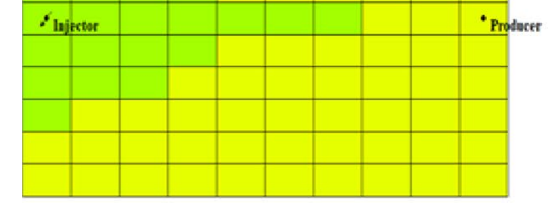

(e)

Polymer flooding

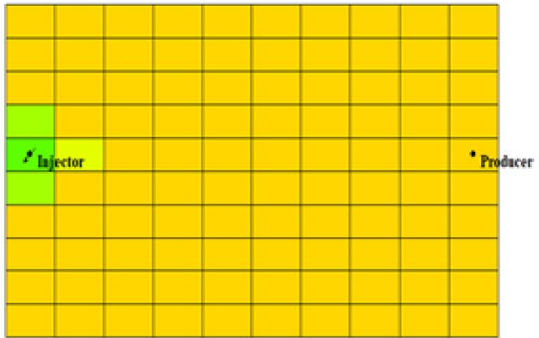

(g)

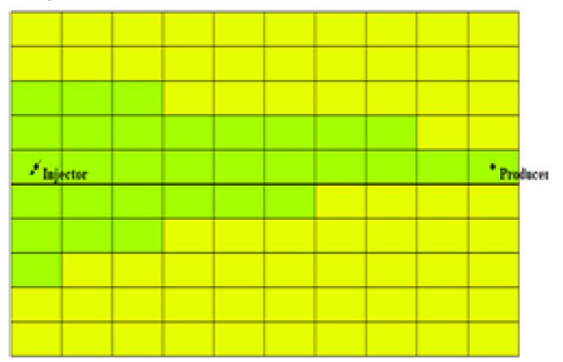

(i)
$\mathrm{T}=5$ years

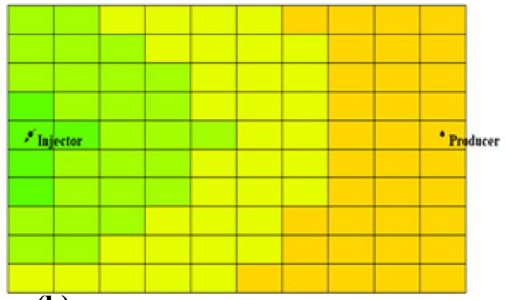

(b)

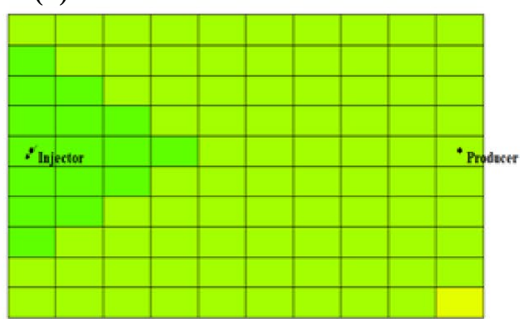

(d)

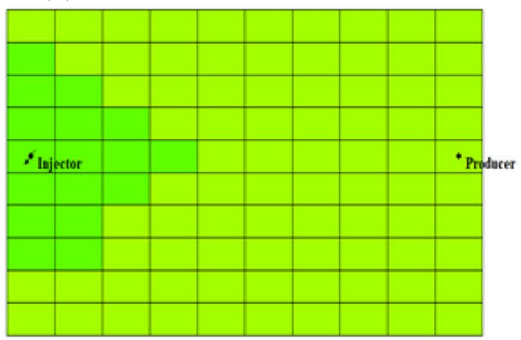

(f)

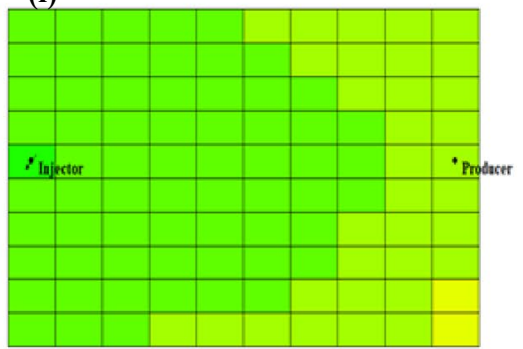

(h)

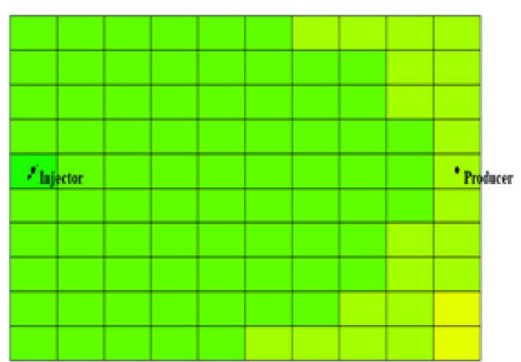

(J)

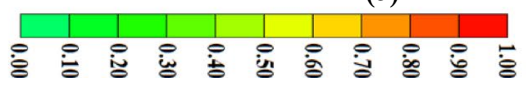

Fig. 6 Residual oil saturation 


\subsection{2 $\mathrm{S}_{\text {or }}$ after $\mathrm{CO}_{2}$ flooding}

For the $\mathrm{CO}_{2}$ flooding, the $\mathrm{S}_{\text {or }}$ reduced from 0.69 to 0.42 as depicted in Fig. $6 \mathrm{c}$ and d. The reduction in oil saturation is because the gas flow through the centre of the pores, and oil/water drained around the edges of the gas. As the residual oil reduction was lower than in water flooding as presumed, it remains unsatisfactory. The shape of oil mobilization obtained from the simulation indicates non uniform speed of the gas as seen by the appearance of the V-shape and the sharp pinch out. Moreover, the shape at the end of the simulation in Fig. $6 \mathrm{~d}$ showed oil accumulation near the producer where the gas was not able to move it. This phenomena maybe attributed to the fact that as $\mathrm{CO}_{2}$ injection started the oil dissolution occurrence, which favour the pressure gradient to help in pushing the oil drops toward production wells. However, only the region near injector well has low $\mathrm{S}_{\text {or }}$ but the region near producer well was slightly higher.

\subsection{3 $\mathrm{S}_{\text {or }}$ after $\mathrm{CO}_{2}$-WAG flooding}

$\mathrm{CO}_{2}$-WAG flooding was applied to overcome the low oil mobilization during the $\mathrm{CO}_{2}$ flooding, the results show that the $\mathrm{S}_{\text {or }}$ trapped after $\mathrm{CO}_{2}$-WAG is 0.32 as seen in Fig. $6 \mathrm{e}$ and $\mathrm{g}$. A reduction of $10 \%$ in $\mathrm{S}_{\text {or }}$ compared to $\mathrm{CO}_{2}$ flooding was obtained. The reduction of the $\mathrm{S}_{\text {or }}$ was expected due to the microscopic displacement efficiency improvement for $\mathrm{CO}_{2}$-WAG injection. The shape of the oil mobilization front in Fig. 6e show less sharp $V$-shaped due the lower gas velocity, which proved the enhancement of oil flow. Moreover, it worth to state that; as much as this case is suitable candidate for WAG, the hazard of water blocking cannot be ignored.

\subsection{4 $\mathrm{S}_{\text {or }}$ after polymer flooding}

The polymer flooding results showed Sor of 0.29 Fig. $6 \mathrm{~g}$ and $h$, the reduction of oil saturation was significantly better than water flooding. The results justified that the polymer addition modified the water flood viscosity. The polymer solution performed at its best in water wet system [32]. Even though the polymer flooding was able to sweep most of the oil, we could see a U-homogenous sweep between the area of injector and producer well. Which is consistent with previous work of Falode and Idoko (2017), they reported a relatively higher contrast of oil saturation in the region between injectors and producer in any P-I pattern

\subsubsection{Sor after PAG flooding}

The lowest $\mathrm{S}_{\text {or }}$ recorded was for PAG flooding which was 0.28 (Fig. $6 \mathrm{i}$ and j). The shape of the flooding indicates uniformed U-shape compared to the gas flooding and WAG. This is because in PAG, the water was used to delay gas breakthrough, improve gas performance and polymer was used to improve the sweep efficiency. These results agree with the previous work of $\mathrm{Li}$ (2014) where he found out that PAG flooding had a lower $\mathrm{S}_{\text {or }}$ compared polymer and water flooding. The effect of PAG on the remaining oil saturation is in contrast with both polymer flooding. This could have resulted from the gas reducing the viscosity of the polymer at the end of the injection, which could be useful to reduce the (polymer-water) flooding resistance factor. By looking at the model within the two years, it was observed that the (water/polymer) resistance factor is lower in PAG as seen in Fig. 7.

\subsection{Gas oil ratio}

The gas-oil ratio (GOR) recorded the highest for $\mathrm{CO}_{2}$ flooding. The peak $\mathrm{GOR}$ for $\mathrm{CO}_{2}$ flooding was $1.27 \mathrm{E}+07 \mathrm{ft} 3 / \mathrm{bbl}$ at the end of the injection as shown in Fig. 8. GOR larger than $5 \mathrm{Mscf} / \mathrm{bbl}$ is seen as gas breakthrough (Li 2014). For the next case, $\mathrm{CO}_{2}$-WAG flooding (Fig. 8b) whereby the peak $\mathrm{GOR}$ recorded was $3.83 \mathrm{E}+06 \mathrm{ft} 3 / \mathrm{bbl}$. The GOR of $\mathrm{CO}_{2}-\mathrm{WAG}$

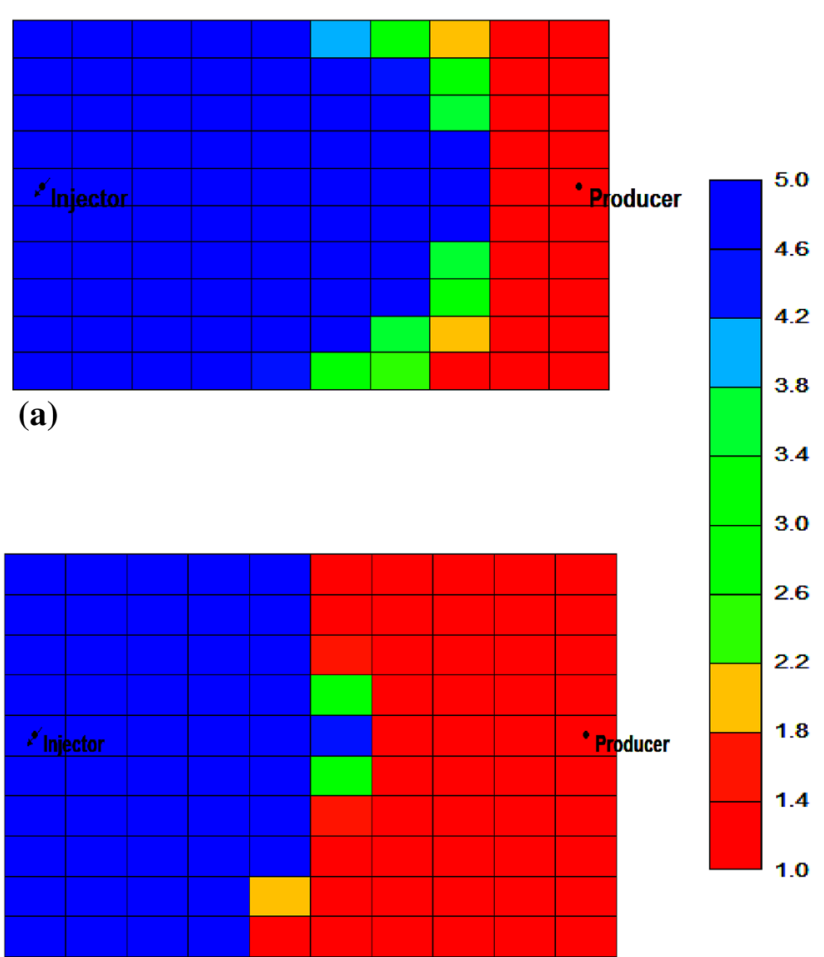

(b)

Fig. 7 Water flow resistance - a PAG flooding, b Polymer flooding 

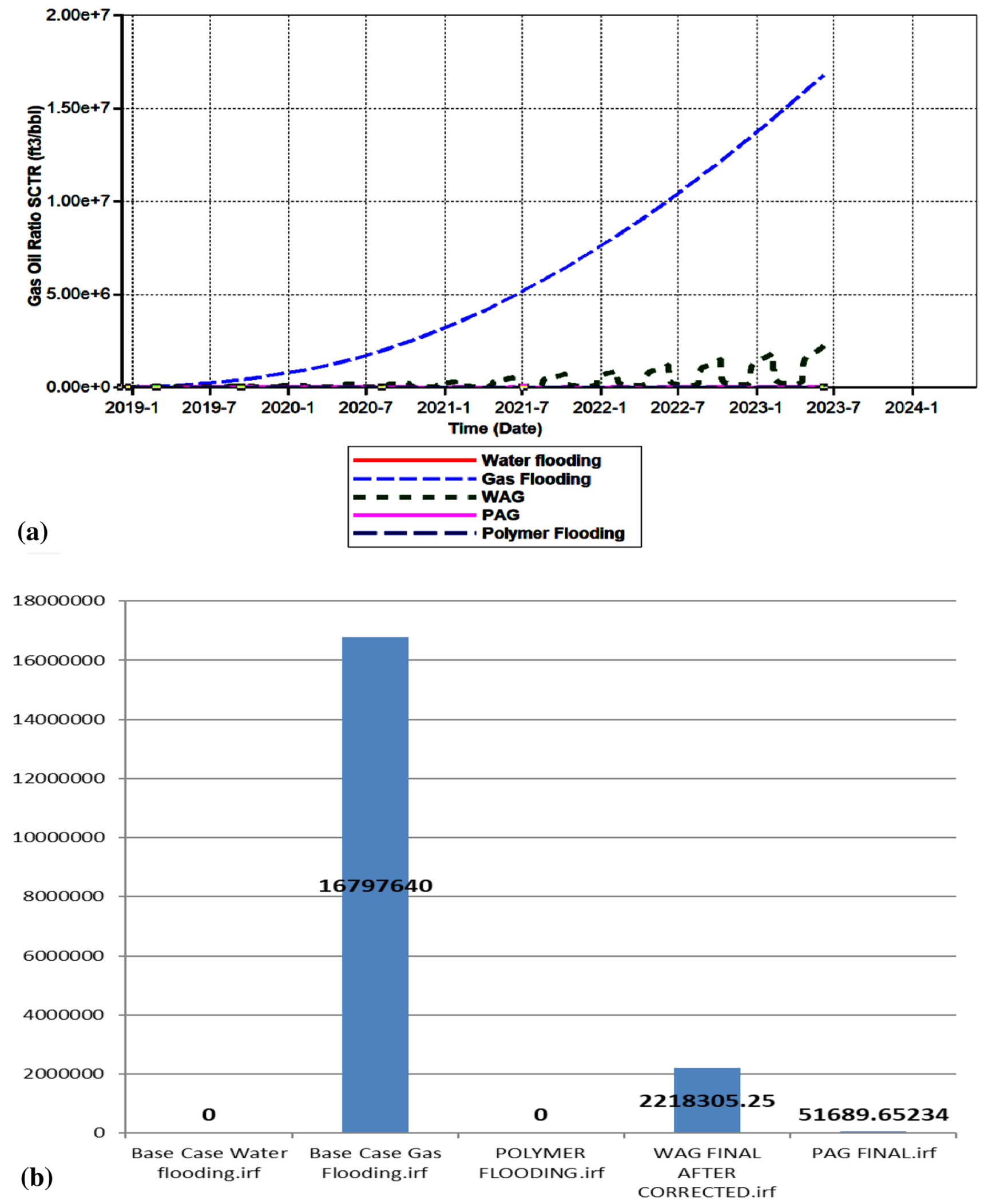

Fig. 8 Gas oil ratio - a simulation result $\mathbf{b}$ column chart representing values of GOR 
flooding was lower compared to that $\mathrm{CO}_{2}$ flooding due to lower production of gas thus slower gas breakthrough. Since there was no significant gas breakthrough found in PAG process, PAG was said to have delayed the breakthrough. The GOR of PAG flood $\left(5.17 \mathrm{E}+04 \mathrm{ft}^{3} / \mathrm{bbl}\right)$ was much lower than $\mathrm{CO}_{2}$ and $\mathrm{CO}_{2}$-WAG. PAG flood has reduced the gas production and more $\mathrm{CO}_{2}$ was captured in the reservoir as seen in Fig. 8b. This result agrees with previous simulation work conducted by Yongzhi Yang et al. (2018), where they found GOR in PAG lower than both of gas flooding and WAG process.

\section{Conclusions}

This research underlined the importance of the effect of combining different fluid or chemical additives with $\mathrm{CO}_{2}$ during the flooding. The research provided evidence on the potentiality of polymer as additive to improve fluid flow in the presence of three phases. The complexity of using $\mathrm{CO}_{2}$ in homogeneous high permeability reservoirs could be lessen by polymer addition. Based on the results of this study, PAG flooding had the highest recovery factor of $56 \%$ with incremental recovery of $16 \%$. Furthermore, controllable water cut of $83 \%$ was achieved during the 5 years period, which is lower by $13 \%$ compared to traditional water flooding. The residual oil saturation was effectively reduced up to $60 \%$ from the initial oil saturation. The GOR during the PAG was the lowest and limit to the range of $5.17 \mathrm{E}+04 \mathrm{ft}^{3} / \mathrm{bbl}$. The results indicate very promising results toward using the polymer to enhance $\mathrm{CO}_{2}$-WAG process. The study is limited to the type of polymer used since it is more used in gel application. Moreover, PAG is favoured for the highly permeable reservoir and can contribute significantly to higher field's expected oil recovery and water cut long term control. Also, the use of polymer showed significant reduction in $\mathrm{CO}_{2}$ production and further could improve the green $\mathrm{CO}_{2}$ utilization.

Funding This research was conducted in Universiti Teknologi Malaysia Reservoir Engineering Lab. No Fund has been received for the study.

\section{Compliance with ethical standards}

Conflict of interest The authors declare that they have no conflict of interest.

\section{References}

1. Han J, Lee M, Lee W, Lee Y, Sung W (2016) Effect of gravity segregation on $\mathrm{CO}_{2}$ sequestration and oil production during $\mathrm{CO}_{2}$ flooding. Appl Energy 161:85-91

2. Lan Y, Yang Z, Wang P, Yan Y, Zhang L, Ran J (2019) A review of microscopic seepage mechanism for shale gas extracted by supercritical $\mathrm{CO}_{2}$ flooding. Fuel 238:412-424
3. Al-Bayati D, Saeedi A, Myers M, White C, Xie Q, Clennell B (2018) Insight investigation of miscible SCCO2 Water Alternating Gas (WAG) injection performance in heterogeneous sandstone reservoirs. J CO2 Util 28:255-263

4. Abusahmin BS, Karri RR, Maini BB (2017) Influence of fluid and operating parameters on the recovery factors and gas oil ratio in high viscous reservoirs under foamy solution gas drive. Fuel 197:497-517

5. Yuan C, Zhang Z, Liu K (2015) Assessment of the recovery and front contrast of $\mathrm{CO}_{2} \mathrm{EOR}$ and sequestration in a new gas condensate reservoir by compositional simulation and seismic modeling. Fuel 142:81-86

6. Kumar S, Mandal A (2017) A comprehensive review on chemically enhanced water alternating gas $/ \mathrm{CO}_{2}$ (CEWAG) injection for enhanced oil recovery. J Petrol Sci Eng 157:696-715. https ://doi.org/10.1016/j.petrol.2017.07.066

7. Alzayer H, Sohrabi M (2018) Water-alternating-gas injection simulation-best practices. In: SPE EOR conference at oil and gas West Asia. Society of Petroleum Engineers

8. Kamali F, Hussain F, Cinar Y (2015) A laboratory and numerical-simulation study of co-optimizing $\mathrm{CO}_{2}$ storage and $\mathrm{CO}_{2}$ enhanced oil recovery. SPE J 20(06):1227-2221

9. Janiga D, Czarnota R, Stopa J, Wojnarowski P, Kosowski $P$ (2017) Performance of nature inspired optimization algorithms for polymer enhanced oil recovery process. J Petrol Sci Eng 154:354-366

10. Abbas $A H$, Sulaiman WRW, Jaafar MZ, Gbadamosi AO, Ebrahimi SS, Elrufai A (2018) Numerical study for continuous surfactant flooding considering adsorption in heterogeneous reservoir. J King Saud Univ Eng Sci. https://doi.org/10.1016/j.jksue s.2018.06.001

11. Li W, Dong Z, Sun J, Schechter DS (2014) Polymer-alternatinggas simulation: A Case Study. In: SPE EOR conference at oil and gas West Asia. Society of Petroleum Engineers

12. Li W, Schechter DS (2014) Using polymer alternating gas to maximize $\mathrm{CO}_{2}$ flooding performance. In: SPE energy resources conference. Society of Petroleum Engineers

13. Li W, Schechter DS (2014) Using polymer alternating gas to maximize $\mathrm{CO}_{2}$ flooding performance for light oils. In: SPE EOR conference at oil and gas West Asia, Muscat, pp 16-18

14. Unsal E, Ten Berge A, Wever D (2018) Low salinity polymer flooding: lower polymer retention and improved injectivity. $J$ Petrol Sci Eng 163:671-682

15. Zhang Y, Huang SS, Luo P (2010) Coupling immiscible CO2 technology and polymer injection to maximize EOR performance for heavy oils. J Can Petrol Technol 49(05):25-33

16. Majidaie S, Khanifar A, Onur M, Tan IM (2012) A simulation study of chemically enhanced water alternating gas (CWAG) injection. In: SPE EOR conference at oil and gas West Asia. Society of Petroleum Engineers

17. Jeong MS, Cho J, Choi J, Lee JH, Lee KS (2014) Compositional simulation on the flow of polymeric solution alternating $\mathrm{CO}_{2}$ through heavy oil reservoir. Adv Mech Eng 6:978465

18. Kong X, Delshad M, Wheeler MF (2015) A numerical study of benefits of adding polymer to WAG processes for a pilot case. In: SPE reservoir simulation symposium. Society of Petroleum Engineers

19. Jamal MS, Al-Nuaim S, Awotunde AA, Khan RA (2016) Optimal parameter selection in a polymer alternating gas PAG process. In: SPE Kingdom of Saudi Arabia annual technical symposium and exhibition. Society of Petroleum Engineers

20. Yang Y, Li W, Zhou T, Dong Z (2018) Using polymer alternating gas to enhance oil recovery in heavy oil. In: IOP conference series: earth and environmental science, vol 1. IOP Publishing, p 012182 
21. Chen X, Feng Q, Wu X, Zhao G (2016) A pilot numerical simulation case study for chemical EOR feasibility evaluation. J Petrol Explor Prod Technol 6(2):297-307

22. Saha R, Uppaluri RVS, Tiwari DP (2019) Impact of natural surfactant (Reetha), polymer (Xanthan Gum) and silica nanoparticles to enhance heavy crude oil recovery. Energy Fuels 25:256

23. Manichand RN, Seright R (2014) Field vs. laboratory polymerretention values for a polymer flood in the tambaredjo field. SPE Reserv Eval Eng 17(3):314-325

24. Gonzalez-Tello P, Camacho F, Blazquez G (1994) Density and viscosity of concentrated aqueous solutions of polyethylene glycol. J Chem Eng Data 39(3):611-614

25. Zhou X, Yuan Q, Zhang Y, Wang H, Zeng F, Zhang L (2019) Performance evaluation of $\mathrm{CO}_{2}$ flooding process in tight oil reservoir via experimental and numerical simulation studies. Fuel 236:730-746

26. Lake LW, Walsh MP (2008) Enhanced oil recovery (EOR) field data literature search. Department of Petroleum and Geosystems Engineering University of Texas at Austin, Austin

27. Kohata A, Willingham T, Yunus Khan M, Al Sowaidi A (2017) Extensive miscible water alternating gas WAG simulation study for a giant offshore oil field. In: SPE Abu Dhabi international petroleum exhibition \& conference. Society of Petroleum Engineers
28. Xie C, Lv W, Wang M (2018) Shear-thinning or shear-thickening fluid for better eor?-A direct pore-scale study. J Petrol Sci Eng 161:683-691

29. Al-Shakry B, Shiran BS, Skauge T, Skauge A (2018) Enhanced oil recovery by polymer flooding: optimizing polymer injectivity. In: SPE Kingdom of Saudi Arabia annual technical symposium and exhibition. Society of Petroleum Engineers

30. Song Z, Li Z, Wei M, Lai F, Bai B (2014) Sensitivity analysis of water-alternating- $\mathrm{CO}_{2}$ flooding for enhanced oil recovery in high water cut oil reservoirs. Comput Fluids 99:93-103

31. Wang D-G, Hu Y-L, Sun J-J, Li Y (2016) Estimation of the wateroil-gas relative permeability curve from immiscible WAG coreflood experiments using the cubic B-spline model. Petrol Sci 13(3):507-516

32. Touray S (2013) Effect of water alternating gas injection on ultimate oil recovery. Master of Engineering Dalhousie University, p 25

Publisher's Note Springer Nature remains neutral with regard to jurisdictional claims in published maps and institutional affiliations. 